\title{
FUTURE-SE: O ULTIMATO NA UNIVERSIDADE ESTATAL BRASILEIRA
}

\author{
JoÃo DOS ReIS SILVA JÚNIOR ${ }^{1}$ \\ Everton Henrique Eleutério Fargoni ${ }^{2}$
}

\begin{abstract}
RESUMO: O artigo analisa as mudanças políticas que redefiniram e estão redefinindo a educação superior brasileira e faz apontamentos para análise da correlação das forças econômicas com o momento histórico do Brasil, tendo origem na década final do século XX e se estendendo até o ano 2020. Caracteriza a composição do Programa Institutos e Universidades Empreendedoras e Inovadoras - Future-se, analisando o contraditório por meio dos intentos e elementos neoliberais introduzidos no texto do projeto. Finaliza, então, descortinando a Reforma do Aparelho do Estado no contexto brasileiro nas duas primeiras décadas do século XXI, por meio do novo regime econômico mundial.
\end{abstract}

Palavras-chave: Capitalismo acadêmico. Educação superior. Future-se. Reforma do Estado.

\section{FUTURE-SE: THE ULTIMATUM IN THE BRAZILIAN STATE UNIVERSITY}

\begin{abstract}
The article analyzes the political changes that have redefined and are redefining Brazilian higher education and makes notes for analyzing the correlation of economic forces with the historical moment of Brazil, originating in the late decade of the $20^{\text {th }}$ century and extending to the year 2020. The paper characterizes the composition of the Programa Institutos e Universidades Empreendedoras e Inovadoras (Entrepreneurial and Innovative Institutes and Universities Program) - Future-se, analyzing the contradictory through the intentions and neoliberal elements introduced in the text of the project. It ends by unveiling the Reform of the State in the Brazilian context in the first two decades of the $21^{\text {st }}$ century through the new world economic regime.
\end{abstract}

Keywords: Academic capitalism. Future-se. Higher education. State Reform. 


\title{
FUTURE-SE: EL ULTIMÁTUM EN LA UNIVERSIDAD ESTATAL BRASILEÑA
}

\begin{abstract}
RESUMEN: El artículo analiza los cambios políticos que han redefinido y están redefiniendo la educación superior brasileña y toma notas para analizar la correlación de las fuerzas económicas con el momento histórico de Brasil, que se originó a fines de la década del siglo XX e se extendió hasta el año 2020. Caracteriza la composición de la Programa Institutos e Universidades Empreendedoras e Inovadoras (Programa de Institutos y Universidades Empresariales e Innovadores) - Future-se, analizando lo contradictorio a través de las intenciones y elementos neoliberales introducidos en el texto del proyecto. Termina con la presentación de la Reforma del Estado en el contexto brasileño en las dos primeras décadas del siglo XXI a través del nuevo régimen económico mundial.
\end{abstract}

Palabras clave: Capitalismo académico. Educación universitaria. Future-se. Reforma del Estado.

\section{Introdução}

A

s duas primeiras décadas do século XXI estão marcadas por numerosos momentos históricos de níveis local e planetário, intensamente significativos para o entendimento do que acontece no pandêmico ano de 2020 no Brasil. Indubitavelmente, o mais evidente marco a indicar mudanças na sociedade brasileira consiste nas Jornadas de Junho de 2013, eventos que foram marcados por manifestações em todo o país, sem reivindicações claras, seguidos da tomada simbólica de poder, quando o movimento, sem liderança, avançou para a Esplanada dos Ministérios, provocando literais combustões na entrada principal do Palácio do Itamaraty. Esse acontecimento registrou de maneira clara e aguda o fim do Pacto da Nova República. As consequências foram de grande monta: a forma política mudou; era impossível conhecer a sociedade, apenas facções de classe, sem lideranças, e um objeto específico de reinvindicação. A sociedade brasileira encontrava-se à deriva.

No âmbito acadêmico, pesquisadores buscavam objetos que não existiam no concreto, pois os sentidos e a razão estavam no horizonte dos fenômenos e, mesmo com o conjunto de fatos, o Brasil e, pormenor, a Academia, ainda em 2018, ano da segunda eleição presidencial pós-Jornadas de Junho, não haviam decifrado 2013. Dessa maneira, o fatídico ano eleitoral de 2018 é marcado na história por meio da coleção de incógnitas. A crise de hegemonia ganhou terreno e o desenho político no Brasil, após o impeachment de Dilma Rousseff, iniciara a consumação de medidas principiadas na década de 1990.

Concluído o ano de 2018 com a vitória de Jair Messias Bolsonaro (ex-PSL) na eleição presidencial, a nação brasileira adentrava uma nova fase, não de enigmas, mas de prenúncios, os quais, mais severamente postos pelo novo Presidente da República, foram marcados por ataques às instituições e aniquilação de direitos. Contudo, grande parte da população brasileira dedicou forte apoio a sua candidatura, préstimo proveniente da insatisfação com os governos anteriores, da decadência econômica do país e do desejo de renovação instaurado por meio de diversos grupos, que vão de instituições religiosas a empresários de vários meios.

Marcada por violentos atos - físicos e virtuais -, a eleição de 2018 deixou uma fratura aberta na política brasileira. O povo, que aspirava por renovação, foi persuadido por novos recursos de atração de votos, como as redes sociais, e elegeram um político veterano, o qual, durante 28 anos como Deputado Federal, 
teve como histórico a baixa produtividade no exercício político. Eleito com o inteligente uso das tecnologias, Bolsonaro, em sua campanha, usou como artifícios eleitoreiros o medo do povo e valores morais, explorando o imaginário coletivo em razão do alto índice de desemprego, da crise econômica, de pautas identitárias e, sobretudo, da indignação com antigos governos - acentuada pela corrupção e não dedicada contra o sistema desigual, o que levou o capitalismo brasileiro a ter intensificação da máquina neoliberal a partir de janeiro de 2019.

Para contextos como esse, Bauman (2010) deslindou que o capitalismo funciona como um parasita que individualiza as mazelas sociais, para que o sistema desigual permaneça intacto. A responsabilidade pelas desigualdades e por tudo que gera insatisfação é do indivíduo: foi ele que não se esforçou o bastante ou que não fez por merecer uma realidade mais satisfatória. Ou seja, o sistema capitalista não responsabiliza as pessoas pelas injustiças, pois, no capitalismo, cultua-se o medo. Seguindo essa lógica, nota-se uma nova fase da República, estabelecida pelo medo e o incentivo da mentalidade meritocrática no meio de um cenário de confrontos, privatizações, autoritarismo e descaso com a educação, descaso esse de que deriva nosso maior destaque, a Educação Superior, maior âmbito de produção de conhecimento na fase mais lúgubre de sua história no Brasil.

O súdito ideal do governo totalitário não é o nazista convicto, nem o comunista convicto, mas aquele para quem já não existe a diferença entre fato e ficção (isto é, a realidade da experiência) e a diferença entre o verdadeiro e o falso (isto é, os critérios do pensamento) (ARENDT, 1997 apud KAKUTANI, 2018, p. 55).

Nessa conjuntura, das Jornadas de Junho de 2013 à eleição de Bolsonaro, o campo da educação superior pública recebeu novos intentos de revisionismo e questionamentos sobre sua finalidade na sociedade, por meio da propagação de notícias falsas e de inverdades sobre sua configuração - conduta provocadora reproduzida por grande parte do eleitorado de Bolsonaro, dado não entenderem como funciona a universidade pública em razão da difusa comunicação da Academia com a complexa sociedade civil. Todavia, o intuito principal foi envolver as universidades, em especial as Universidades Federais e os Institutos Federais, no movimento de privatização das estatais.

Advindo dessa racionalidade, em julho de 2019, foi apresentado pela Secretaria de Educação Superior (SESu/MEC) o Programa Institutos e Universidades Empreendedoras e Inovadoras - Future-se ${ }^{1}$, projeto que tem como argumento principal o fortalecimento da autonomia financeira das IFES, transformando-as em Organizações Sociais $(\mathrm{OS})^{2}$, para a busca de fomento e captação de recursos. Em suma, o objetivo parece oportuno; no entanto, faz-se necessário conjeturar e analisar esse programa diante da história recente da política e do capitalismo brasileiros, a fim de evidenciar a lógica dessa profunda reforma na estrutura da educação superior pública federal. Esse é o propósito deste artigo.

\section{O Contexto Político para o Future-se}

O Programa Institutos e Universidades Empreendedoras e Inovadoras - "Future-se" pode parecer uma grande novidade positiva no campo acadêmico brasileiro, mas sua disposição constitui-se de uma amálgama de leis e práticas políticas que vêm sendo praticadas desde a década de 1990. Ou seja, para entender o presente momento, é necessária uma breve visada histórica, com início em novembro de 1989, mês em que economistas liberais latino-americanos, funcionários do Fundo Monetário Internacional (FMI), do Banco Mundial e do governo norte-americano reuniram-se por convocação do Institute for International 
Economics, entidade de caráter privado, para discutir medidas econômicas que posteriormente incidiriam em Reformas do Estado em mais de sessenta países. Tal reunião ficou conhecida como Consenso de Washington ${ }^{3}$

O ex-presidente Fernando Collor de Mello Collor (1990-1992) iniciou ações estreitas das medidas provenientes do Consenso de Washington, porém foi “impedido", em razão de iniciativas políticas impopulares. Itamar Franco (1992-1994) assumiu a presidência e buscou novas relações com a estrutura do congresso, procurando resgatar a popularidade do governo e, como o estadista que foi, atuou com planos econômicos sem choques, preparando o campo político nacional para Fernando Henrique Cardoso (FHC) (1995-2002). Foi nos oito anos do governo de FHC que as dez medidas originárias do Consenso de Washington passaram a ser operacionalizadas no Brasil - ideias que integraram e deram base para o Plano Diretor da Reforma do Aparelho do Estado, documento publicado em 1995, que introduziu as mudanças econômicas de natureza neoliberal no Brasil.

FHC acentuou o Pacto Social da Nova República e pôs em prática as ideias do Plano Diretor. No campo acadêmico, tais medidas impactaram de modo direto no lócus universitário público, na forma de trabalho dos professores-pesquisadores e, por conseguinte, na produção de conhecimento. Por exemplo, em 29 de dezembro de 2000, foi instaurada a Lei n. 10.168, que estabeleceu o Programa de Estímulo à Interação Universidade-Empresa para o Apoio à Inovação. Essa lei fez com que as universidades começassem a se orientar por meio de atividades econômicas, transfigurando sua identidade.

Art. $1^{\circ}$. Fica instituído o Programa de Estímulo à Interação Universidade-Empresa para o Apoio à Inovação, cujo objetivo principal é estimular o desenvolvimento tecnológico brasileiro, mediante programas de pesquisa científica e tecnológica cooperativa entre universidades, centros de pesquisa e o setor produtivo (BRASIL, 2000).

Em 7 de setembro de 2001, por meio da Lei n. 10.260 foi disposto o Fundo de Financiamento do Estudante do Ensino Superior (FIES), outra medida que valorizava a expansão de vagas no Ensino Superior, dando ao cidadão brasileiro a oportunidade de graduar-se, porém numa instituição privada. Esses exemplos se proliferaram objetivando a Reforma do Aparelho do Estado Brasileiro, que recuperou as dez medidas econômicas do consenso, e se aperfeiçoaram para a realidade brasileira: flexibilização das leis trabalhistas, mudança jurídica na propriedade privada, controle das finanças dos governos estaduais e municipais, terceirizações irrestritas, privatizações, congelamento de salários dos docentes, entre outros.

Após o governo de FHC, Luiz Inácio Lula da Silva (2003-2010) registrou sua marca na história política brasileira, dando continuidade às práticas políticas provenientes das medidas da Reforma do Aparelho do Estado. No campo político-acadêmico, ao mesmo tempo que realizou a expansão e a interiorização da educação superior pública federal (REUNI, entre outros), Lula fortaleceu políticas focais, como o FIES e o PROUNI, práticas correntes de um governo marcado pelo populismo e por conciliações -fato que pôde ser observado em 26 de maio de 2010, em seu discurso sobre o Marco do Consenso Universidade-GovernoEmpresa, na 4a Conferência de Ciência, Tecnologia e Inovação: o Presidente, junto do Ministro da Educação, Fernando Haddad, verbalizou as tendências em construção do campo científico-acadêmico estreito da produção de conhecimento sob demanda do capital financeiro:

Lula enfatizou que presidentes anteriores nunca se reuniram com reitores. "Presidente da República não se reunia com reitor. Eu me reuni todos os anos, construindo políticas de educação juntos e ficou muito mais fácil", ressaltou o Presidente. "Só temos uma dívida com eles, que é a autonomia universitária, que ainda temos que resolver", afirmou Lula (ANDIFES, 2010). 
Com Dilma Rousseff (2011-2016) não foi diferente: características do Future-se, que outrora apareceram nas Leis e Políticas focais de FHC e de Lula, também fizeram parte de seu governo. O maior exemplo está na mudança da episteme da ciência brasileira, que constituiu a base da promulgação do BayhDole Act ${ }^{4}$ brasileiro: O Novo Marco Legal de Ciência, Tecnologia e Inovação (ocorrido em $1^{\circ}$ de agosto de 2013 e que dispôs sobre os estímulos ao desenvolvimento de produção científica, à pesquisa e à capacitação tecnológica para a inovação). Esse fato, posteriormente, consolidou-se na Lei n. 13.243, de 11 de janeiro de 2016, que, já em formato de lei, permitiu o compartilhamento de laboratórios, equipamentos, instrumentos, materiais e demais instalações com ICT ou empresas em ações voltadas à inovação tecnológica para consecução das atividades de incubação. Um dos objetivos do Marco Legal foi "facilitar a aproximação de empresas e universidades, incentivando mais pesquisa, desenvolvimento científico e tecnológico e a inovação no país" (SICSÚ; SILVEIRA, 2016).

A presidente Dilma Rousseff destacou que, apesar de o Brasil ter uma "extraordinária capacidade de produzir conhecimento", infelizmente, esse conhecimento ainda não tem se traduzido em inovação produtiva integralmente. Segundo Dilma, com a nova legislação, será possível transformar "ciência básica em inovação" e "inovação em competitividade, gerando um novo ciclo de desenvolvimento econômico". Esses avanços são importantes para a inovação no país. O Marco viabiliza as parcerias público-privadas (PPP), facilitando a articulação com empresas inovadoras, principalmente de porte médio e pequeno (SICSÚ; SILVEIRA, 2016, p. 4-5, grifos nossos).

No mesmo ano, em 31 de agosto de 2016, Dilma Rousseff perdeu o cargo de Presidente da República após três meses de tramitação do processo de impeachment iniciado no Senado. O então vice-presidente Michel Temer (2016-2018) assumiu interinamente a Presidência e retomou, intensamente, as medidas da Reforma do Aparelho do Estado. As principais ações de Temer estavam respaldadas em seu programa, intitulado "Ponte para o Futuro", o qual resgatou políticas de privatização, redução de investimentos sociais e cortes de gastos públicos (ver PEC n. 241 ou PEC n. 55) . Pelos cortes de "gastos" anunciados por Michel Temer, o campo da educação superior foi um dos mais afetados. A redução dos investimentos em Ciência e Tecnologia (C\&T) e Pesquisa e Desenvolvimento (P\&D) levaram a realidade científico-acadêmica brasileira a voltar a índices de dispêndios de 2007, regresso de uma década.

Foi no governo Temer que a ameaça às universidades federais começou a se intensificar, ora pelos cortes de recursos, ora pela forte tendência à privatização das instituições federais, além dos ataques aos direitos dos seus servidores. Para Gomes (2016), a principal parte da privatização seria a previdência de seus servidores, agravando o quadro da precarização das condições de trabalho e a degradação da qualidade do ensino ofertado, como o reajuste da carreira docente por meio da oficialização da Medida Provisória n. 792/2017, ao instituir, por exemplo, o Programa de Demissão Voluntária.

Em 2019, após conturbada eleição, Jair Bolsonaro assumiu a Presidência da República. Para Ministro da Economia, Bolsonaro escolheu Paulo Guedes, conhecido pelo radical currículo econômico neoliberal, agindo, por exemplo, na reorganização econômica de países da periferia do capitalismo mundial e tendo como maior exemplo o Chile 6 , o qual,no ano de 2019, registrou, no cotidiano civil, convulsões sociais provenientes das reformas neoliberais no país por meio de intensos protestos da população.

Alinhado com as práticas internacionais neoliberais e de mesma postura ideológica, Bolsonaro convidou, para o Ministério da Educação, o até então desconhecido Ricardo Vélez Rodríguez, inexperiente na área e na função. Vélez ficou no cargo até 8 de abril de 2019, depois de sucessões de ideias impopulares 
questionadas pela Câmara de Deputados e por educadores em todo o país. Para seu lugar, Bolsonaro designou Abraham Weintraub, professor da Universidade Federal de São Paulo (Unifesp).

Segundo apuração do Jornal do Campus da Universidade de São Paulo (USP, 2019), Weintraub "[D]edicou sua vida ao mercado financeiro, como diz sua biografia no currículo. Seu único vínculo com a educação brasileira foi, além de estudante, professor da Unifesp, começando em 2014, e orientou apenas um aluno durante seu período na instituição". Notadamente, não somente o perfil do novo Ministro da Educação estava alinhado com o propósito ideológico de Bolsonaro, mas ele também compactuava com a concepção de Guedes no Ministério da Economia. A título de exemplo, Weintraub anunciou, no final de abril de 2019, o contingenciamento de $30 \%$ do orçamento para verbas de custeio e investimentos das instituições federais. O Ministro se apoiou na ideia de que a liberação da verba retida dependia da Reforma da Previdência e da retomada da economia - outra reforma que se utilizava das mesmas ideias originárias do Consenso de Washington, operacionalizadas por meio do Plano Diretor da Reforma do Aparelho do Estado.

O contingenciamento de verbas provocou protestos por todo o Brasil, virtualmente e nas ruas. Alunos e professores manifestaram-se contra as medidas do governo, o qual, em vez de dialogar com a comunidade acadêmica, assumiu atitudes impopulares sem diálogo com o povo. A medida resultou em cortes de bolsas de iniciação científica e pós-graduação, financiamentos que entraram no pacote de contingenciamento e antecederam a sintomática apresentação do Programa Future-se, em julho de 2019.

\section{O "Future-se"}

$\mathrm{Na}$ apresentação do programa, Abraham Weintraub retomou o antigo discurso da reorganização da universidade sob a orientação do mercado, principalmente atrelada à tecnociência, o que encontra boa guarida entre muitos dos professores-pesquisadores que defendem o novo modelo institucional: $a$ Universidade Empreendedora. Na sua primeira versão, o texto do Future-se, antes de entrar em consulta pública, caracterizava-se, principalmente, em três eixos condutores: 1) Gestão, Governança e Empreendedorismo; 2) Pesquisa e Inovação; e 3) Internacionalização. Observe-se que os três itens permanecem como base do programa, porém, no decorrer das três versões do texto, novos elementos foram delineados a partir dos eixos principais.

Um dos destaques derivados dos três tópicos é a proposta de que as universidades que aderirem ao programa poderão realizar contratos de gestão com Organizações Sociais (OS), proposição essa que se ordena rigorosamente com os quatro setores dispostos no Plano Diretor da Reforma do Aparelho do Estado (1995):

(1) o núcleo estratégico do Estado, (2) as atividades exclusivas do Estado, (3) os serviços não exclusivos ou competitivos, e (4) a produção de bens e serviços para o mercado. [...] Na União, os serviços não exclusivos de Estado mais relevantes são as universidades, as escolas técnicas, os centros de pesquisa, os hospitais e os museus. A reforma proposta é a de transformá-los em um tipo especial de entidade não estatal, as organizações sociais. A ideia é transformá-los, voluntariamente, em "organizações sociais", ou seja, em entidades que celebrem um contrato de gestão com o Poder Executivo e contem com a autorização do Parlamento para participar do orçamento público (BRESSER-PEREIRA, 1996, p. 286).

A lógica do Future-se, como ficou demonstrado alhures, não se explica tão somente em função de uma medida de mudança na episteme da ciência - ele é, também, programa de privatização de bens patrimoniais e recursos públicos, direcionando-os no modelo de autonomia financeira, à 
mercê das grandes corporações nacionais e mundiais, reorganizando as universidades públicas em OS dependentes do setor privado e vendendo serviços. Tudo isso indica a direção para a mercantilização máxima, além de integrar uma cruzada ideológica, embora esse tópico não apareça de modo direto nas entrelinhas, mas nas manifestações do governo e do Ministério da Educação (vide o núcleo ideológico assumidamente reacionário). Nota-se, no projeto, que o desmonte não se destina apenas às universidades, mas a todo o sistema de ciência e tecnologia do país, que, além das universidades, contém as agências públicas de fomento, responsáveis pelo financiamento de quase $90 \%$ da produção científica do país, aprofundando o processo de dependência científica e tecnológica (LEHER, 2018).

No aprofundar dos traços inaugurados ou sugeridos pela Reforma do Estado, que se configura numa cultura institucional marcada pela pesquisa aplicada, por cursos aligeirados e modalidades de ensino apoiadas em novas tecnologias de informação e comunicação, por processos de regulação e controle externos, e pela gradativa perda da autonomia universitária, associada a heteronomia de gestão e nova relação entre a educação superior e o setor empresarial, está sob indução e apoio do governo, tal como há tempos já se observava nos países de economia central e cuja acentuação ocorreu, no caso da União Europeia, em especial, a partir do Processo de Bolonha (SGUISSARDI; SILVA JÚNIOR, 2013, p. 138).

A predominância da racionalidade econômica na cultura das universidades e faculdades é um alerta que vem sendo sinalizado há anos: produzir conhecimento sob a demanda do mercado produtivo passará, por meio do Future-se, a ser normalizado; ou seja, a ciência terá seu tempo comprimido, deixando de ser ciência para ser tecnociência. De acordo com Silva Júnior e Fargoni (2019), o Future-se supervalorizará a tecnociência sob a ótica do mercado científico global e reduzirá subitamente o fundo público para investimento em desenvolvimento, pesquisa, ciência e tecnologia, ao se inspirar na fórmula internacionalizada da universidade norte-americana, a qual há muito segue as orientações do World Class University ${ }^{7}$. Essa logicidade encontra-se nos textos de 2019 e 2020 do Future-se, enviado para votação no Congresso por meio da Mensagem n. 302, no dia 26 de maio de 2020.

Art. $1^{\circ}$. Itens V e VI - fomentar a promoção da visão empreendedora e estimular a internacionalização das universidades e institutos federais. Art. $2^{\circ}$. As medidas previstas nesta lei devem ser orientadas pelos princípios de legalidade, impessoalidade, moralidade, publicidade, economicidade e eficiência [...] Art. $3^{\circ}$. IX - startup: modelo de negócios diferenciado, com ideia inovadora de produtos e serviços, perfil empreendedor e inspirador dos sócios criadores, visando à obtenção de ganhos econômicos a partir da assunção de riscos.

Por meio desse processo, será instituído, na universidade, sistema meritocrático, em que pesquisadores desafiarão uns aos outros em busca de verbas provenientes de empresas privadas. Além disso, haverá a concorrência entre as universidades para ranquearem-se bem, a fim de conquistarem parcerias públicos-privadas, que representarão o fundo predominante de financiamento, dado que pouco será provido do Tesouro Nacional. Essa é a lógica que vem se desenhando desde a Reforma do Aparelho do Estado: a redução, ao máximo, da Esfera Pública e o aumento, ao máximo, da Esfera Privada; ou seja, a criação de um grande mercado com os direitos dos cidadãos. Desse modo, o 
conhecimento produzido não será público e a tentativa será de que as universidades constituam organizações à imagem e semelhança das empresariais (CHAUÍ, 2001), cujo acesso será muito mais moroso.

O conhecimento privatizado torna-se muito mais inacessível e, talvez, restrinja a potência de descobertas e inovações. Além disso, mais uma vez, o mercado mundial se põe sobre a liberdade acadêmica. A ciência básica, orientada pela tecnologia básica, produz formas estreitas de conhecimento e uma educação não orientada segundo os direitos públicos dos cidadãos, processo que mina a riqueza da educação superior (SILVA JÚNIOR, 2017, p. 140).

\title{
Implicações do Future-se nas Universidades
}

\section{Pesquisa, Desenvolvimento Tecnológico e Inovação}

\begin{abstract}
A partir de meados do século XIX, essa pulsão fetichista por novas formas de tecnologia a qualquer preço promoveu a fusão entre ciência e tecnologia. Depois disso, ambas evoluíram num abraço dialético. Se, por um lado, o desenvolvimento científico sempre dependeu de novas tecnologias, como o telescópio e o microscópio, por outro, a incorporação de conhecimento científico a novas tecnologias tornou-se o cerne da atividade empresarial da inovação tecnológica (HARVEY, 2016, p. 96).
\end{abstract}

Em reação ao Future-se, tanto na esfera política quanto na comunidade acadêmica, os atores envolvidos responderam, em sua maioria, com a antítese do projeto. Embora, ao direcionar tendencialmente a autonomia financeira da universidade, o governo se utilize do pressuposto de que os IFES não perderão a autonomia, ao propor que as instituições se tornem suas parceiras por meio de OS, o governo requer das universidades que passem a uma servidão de contratos, seja com o Estado, seja - principalmente - com grandes corporações, por meio da venda de serviços e do aluguel dos patrimônios. Esse fato se destaca na minuta do Future-se, uma vez que, por meio dos contratos de gestão, as OS poderão atuar na gestão de recursos e patrimônio das instituições; ou seja, são os naming rights ${ }^{8}$ (concessão de direitos públicos) em campi e edifícios e mesmo a venda dos imóveis e laboratório.

Schwartzman et al. advertem que, nesse aspecto, "parece excessivamente otimista a expectativa de que o setor privado aumente significativamente sua participação, seja em atividades conjuntas de pesquisa e inovação tecnológica, seja em doações filantrópicas” (2019). Isso se dá porque o setor produtivo, historicamente, não investe em pesquisa e desenvolvimento, exceto no estado de São Paulo, onde a tecnociência se destaca por muitas parcerias com empresas e com grandes investimentos - o que o Future-se pretende institucionalizar como prática.

Acompanhando essa corrente, os professores-pesquisadores das universidades estatais depararão com a ressignificação de seu trabalho, pois o produto da tecnologia decorrerá, em número maior, sob demanda externa da universidade e o trabalho imaterial superqualificado dos pesquisadores se transformará em trabalho produtivo. Isso significa que, na primeira fase, o pesquisador começará a estranhar o objeto por ele produzido, porque a pauta de pesquisa será posta de fora da universidade. Na segunda fase, estranhará os tempos e a racionalidade do processo do trabalho: a racionalidade agora será voltada para a economia e os tempos serão postos de fora pelas corporações mundiais, sempre articuladas com o capital financeiro. 


\section{Empreendedorismo e Internacionalização}

Em dados mais recentes ${ }^{9}$, mais de $70 \%$ das 63 universidades federais do país rejeitaram o Projeto de Lei Future-se. Ao todo, 43 das 63 universidades federais já se reuniram e analisaram a proposta do governo, apresentando diversas críticas ao projeto. De modo geral, as universidades federais sinalizam que o Future-se não indica nenhuma solução para os problemas dos IFES. A rejeição ao ideal educativo centrado no empreendedorismo defende que se evite o ressecamento da formação filosófica, sociológica, literária, histórica, artística etc. e, sobretudo, da mediação humana na atividade docente e na pesquisa. $\mathrm{O}$ empreendedorismo, baseado na ideia de inovação e desenvolvimento de produtos imediatos para o mercado, simboliza a privatização do trabalho humano e da produção de conhecimento das universidades e dos institutos federais. Todas as atividades fins serão conduzidas pela lógica do Future-se: atender os interesses do mercado e suas empresas.

Nas minutas divulgadas do Future-se, sem paginação, o empreendedorismo aparece em todas as categorias. O capítulo relativo ao empreendedorismo se ancora em lei do governo Dilma, que deu apoio à criação, atração, implantação e consolidação de ambientes promotores de inovação, com foco no estabelecimento de parceria com o setor empresarial, no âmbito da Lei n. 13.243, de 11 de janeiro de 2016, incluídos parques e polos tecnológicos, incubadoras e empresas nascentes de base tecnológica.

Esse trecho induz as universidades federais ao aprimoramento dos modelos de negócios e promoção da marca para gerar o produto da instituição, enquanto busca financiamento de projetos de pesquisa aplicada para que seus projetos de inovação estimulem o surgimento de empresas inovadoras de base tecnológica e, consequentemente, gerem patentes.

Por meio desse movimento, nota-se a radical redução da autonomia universitária a um status de autonomia financeira, não de gestão financeira, patrimonial, didática e científica, conforme se infere do art. 207 da Constituição Federal de 1988: "Art. 207. As universidades gozam de autonomia didático-científica, administrativa e de gestão financeira e patrimonial, e obedecerão ao princípio de indissociabilidade entre ensino, pesquisa e extensão." A liberdade de cátedra desponta com feridas devido à ausência de um diagnóstico acerca do exercício da autonomia pelas universidades e institutos federais; ou seja, o empreendedorismo, como cerne, mudará completamente o éthos do trabalho docente, além de aumentar a perda de soberania e a desnacionalização, em função da busca de prestígio e verbas, asseguradas por muitas empresas, com capital aberto mundialmente.

Ao tratar a educação superior como mercadoria, o Future-se tornará as universidades federais excelentes empresas de pesquisa prestadoras de serviços. Empresas são corporações mundiais articuladas com o capital financeiro para produção de mercadorias e disputa de mercado, ao mesmo tempo que estão aparelhadas pelo imperativo capitalista.

Estará expresso através de um "imperialismo total” (FERNANDES, 1975a) que (a) organiza a dominação externa a partir de dentro e em todos os níveis da ordem social, desde o controle da natalidade, da comunicação e o consumo de massa, até a importação maciça de tecnologia e de uma concepção de educação voltada para a formação da força de trabalho e para a conformação aos valores burgueses; (b) aprofunda as dificuldades para que os países latino-americanos garantam seu crescimento econômico em bases autônomas; e (c) estimula o fato de que, nas economias periféricas, como ocorre com os interesses privados externos, os interesses privados internos estejam empenhados na exploração do subdesenvolvimento como estratégia para garantir sua lucratividade (LIMA, 2005, p. 4). 
Essa lógica imperativa repete-se no eixo da Internacionalização da minuta do Future-se: para elevar a marca das universidades e institutos federais, será necessário ampliar a colaboração e as parcerias internacionais em ensino, pesquisa e extensão, com a facilitação do acesso e a promoção de disciplinas em plataformas on-line. Ou seja, ocorrerá expansão do ensino a distância, regulado por produtos da tecnociência, intercâmbio de professores-pesquisadores e estudantes que estejam envolvidos com pesquisas aplicadas, com garantia de certificação, a fim de registar os altos desempenhos. Produções em periódicos internacionais também serão impulsionadas, com o simples fim de concorrência entre as instituições, no intuito elevarem-se no ranqueamento global de Ensino Superior. O sistema estadunidense de oferta de bolsas a atletas brasileiros com alto rendimento será copiado, porém fora do país.

\section{Mercantilização do Conhecimento}

O processo de produção de conhecimento não atende o tempo cronológico. a ciência não tem relógio e, ao impor a ela metas de atingimento, é-lhe retirado o tempo de reflexão e criação do produto de conhecimento. Por isso, mostramos que a mercantilização atravessa todos os eixos e o trabalho do professor na universidade privatizada deixa de ser voltado para a formação humana e passa a se voltar para o treinamento para o mercado produtivo, nos moldes do capitalismo acadêmico. Segundo Slaughter e Rhodes (2010), esse é o indicativo da mudança da prática cotidiana das universidades, ao se instituir que o fio condutor da Academia é a busca por lucro por meio da comercialização de produtos mercantis produzidos pelas universidades.

O iminente risco desse caminho pode culminar em lacunas e crises similares às dos Estados Unidos, como a acumulação de dívidas das instituições e, principalmente, dos estudantes, uma vez que, dados início do programa e sequência às privatizações, novas medidas poderão ser apresentadas, como a cobrança de mensalidades nas universidades estatais. É isso que ocorre nas universidades norte-americanas, as quais, por serem todas privadas, estão gerando uma nova crise econômica no país, em virtude da alta inadimplência dos estudantes, incapazes de pagar as dívidas provenientes das mensalidades dos cursos superiores, o que supera a dívida nacional com os cartões de crédito. Paulani (2019) aponta esse fato, ao dizer que a economia mundial se modificou, deixando o Regime de Predominância financeira e adotando a nova economia, por meio da sobreacumulação, financeirização e rentismo no sistema global.

Nesse circuito econômico, o Future-se só transita como programa de especulação, mas muda o caráter do trabalho nos centros acadêmicos, que, por sua vez, cada vez mais se aproximará dos dispositivos empresariais, como missão, visão e valores. A respeito disso, destacamos alguns pontos importantes do programa, os quais se estreitam com outros projetos que também vêm sendo discutidos em tempo anterior ao Future-se, com circulação no Congresso:

- Transformação em Apex ${ }^{10}$ da educação brasileira em produto de exportação;

- As universidades que aderirem ao programa poderão realizar contratos de gestão com as OS;

- Os contratos de gestão poderão ser celebrados com os já qualificadas pelo MEC ou por outros Ministérios. Inicialmente, portanto, não haverá a necessidade de chamamento público (grifos nossos);

- Professores em regime de dedicação exclusiva poderão exercer atividade remunerada de pesquisa na OS contratada pela universidade, desde que cumpram sua carga horária ordinária; substituir o idioma sem fronteiras por parcerias com instituições privadas para promover a publicação em periódicos no exterior (grifos nossos); 
- MEC quer fundo de R 102 bilhões para estimular recurso privado em universidades - mais educação de chamamento público (grifos nossos);

- As OS contratadas poderão participar da gestão de recursos e de patrimônio das instituições de ensino. A cessão de servidores das instituições federais para as OS será facultativa. No caso de transferência, a remuneração e os encargos sociais e trabalhistas do servidor ficarão a cargo das OS (grifos nossos);

- Também constituem recursos do fundo a comercialização de bens e produtos com a marca das instituições apoiadas e o valor cobrado de matrículas e mensalidades de pós-graduação lato sensu nas universidades federais. A administração do fundo será privada;

- O plano prevê, entre outros pontos: estabelecer limite de gastos com pessoal das universidades, conforme estabelecido pelo comitê gestor do programa; criar fundo de investimento imobiliário e cessão de uso, concessão, comodato de imóveis (grifos nossos);

- Contratos de gestão com OS poderão atuar na gestão de recursos e de patrimônio das instituições; criar naming rights (ver nota 7) em campi e edifícios; transformar atividades de extensão em atividades culturais para receber incentivos via Lei Rouanet; estabelecer requisitos de transparência, auditoria e compliance, vinculação a índices de governança; remunerar de maneira privada professores com publicações em revistas de ponta e possibilidade de registro de patentes em nome deles (grifos nossos).

Como exaustivamente exposto neste artigo e na maioria dos que tratam sobre o programa Future-se e a Reforma do Aparelho do Estado, tal lei parece organizar as mudanças políticas, deixando de lado as mudanças de regime de acumulação do capitalismo.

\section{Reforma do Aparelho do Estado e o Novo Regime de Crescimento Econômico com Base na Dívida Social}

Por meio do movimento histórico aqui apresentando e do exame do programa Future-se, indagamos as razões para que o Estado seja reformado e por que motivos o seria da maneira instrumentalizada em quase $40 \%$ dos países no planeta. A explicação às indagações encontra-se nos regimes de acumulação. Buscaremos fazer a consideração do regime de predominância financeira para melhor compreender o que até aqui se expôs.

A Reforma do Aparelho de Estado Brasileiro e seu significado no movimento ainda vigente da reforma da universidade estatal foram parte indispensável do programa tratado nesta investigação, esforço analítico que resultou neste artigo. Tal movimento de reforma, contudo, tornou-se mais definido quando o novo modelo de avaliação da Coordenação de Aperfeiçoamento de Pessoal de Nível Superior (CAPES) - cujo início data dos anos 1996 e 1997 - teve sua plena realização no plano institucional das universidades em geral e, em particular, das universidades estatais. Por meio dele, o anfêmero da universidade produziu elementos objetivos das mudanças em curso, demonstradas por meio dos reclamos de colegas, dos vários debates institucionais, das tensas reuniões, da compulsória mudança de gestão dos programas, dos instrumentos institucionais de avaliação, entre outros.

Os contextos político e social brasileiros transformaram-se rapidamente e a Reforma do Estado tornou-se a origem das mudanças de todas as instituições republicanas. Não nos ficavam claras a razão e a forma do Estado Reformado, mas, por meio do plano econômico, os sinais para a compreensão das mudanças resolviam as lacunas. 
A economia que emergiu no pós-Segunda Guerra Mundial produziu historicamente demandas e litígios para a indústria. No âmbito mundial, as exigências estruturais requereram a diminuição de tempo entre a produção científica e sua aplicação em serviços, produtos e processos. Tais características são notórias nas medidas políticas impostas pelos governos brasileiros para o campo acadêmico desde a década de 1990. Por exemplo, a ciência, básica ou aplicada, voltada para o bem público, teve e ainda tem forte pressão para mudança, tendo sido necessárias transições constantes para estabelecer novos tipos de conhecimento, que atendam largas demandas, postas não mais por parâmetros exclusivamente científicos, mas pela financeirização da economia. Silva Júnior e Sguissardi (2020) analisam, por exemplo, políticas públicas formuladas para a área social. Não são políticas sociais, mas econômicas, prontamente apensadas, da mesma forma, da reestruturação e da ressignificação da produção da ciência no Brasil.

Ocorre mudança de paradigmas das políticas públicas brasileiras: do paradigma da demanda social para o paradigma de oferta econômica, em meio a um movimento, a um só tempo, de expansão da esfera privada em detrimento da esfera pública e de hipertrofia do Poder Executivo em detrimento do Poder Legislativo (SILVA JÚNIOR; SGUISSARDI, 2000, p. 277).

A economia converteu-se, pois, no maior fator da inédita epistemologia da ciência acadêmica, diante, especialmente, do posto econômico e bélico que os Estados Unidos passaram a ocupar em grau mundial. Para Silva Júnior (2017, p. 129), “o conhecimento exigido pelas novas corporações, financeiras ou industriais, tem, entre suas redes de trabalho e produção, uma ou mais parcerias com universidades no mundo todo, que se dão de diversas formas, estrategicamente, por meio de transferência de tecnologia" e pela venda de direitos autorais para as próprias universidades. Esse conhecimento, na maioria das vezes, é transferido na forma de inovações sociais e tecnológicas, tipo de conhecimento que denominamos conhecimento-mercadoria.

O conhecimento-mercadoria é voltado para a economia e para o mercado como parcela dos resultados da ciência em seu novo paradigma. O Future-se simboliza essa concepção de produto científico arrojando para a comercialização, ou seja, o conhecimento-mercadoria está pronto para ser transformado em produtos de alta tecnologia, novos processos de produção e serviços, como propósito para lucros imediatos no âmbito econômico. Ademais, ao buscarmos a forma mais geral do conhecimento-mercadoria podemos entendê-la por inovação tecnológica ou parte primária da tecnociência.

O grande problema do capital, até há pouco tempo, resumia-se na redução do gap entre a ciência e a tecnologia e, embora houvesse uma aproximação entre a universidade e a indústria, acontecia, porém, uma demora considerável na resolução dos problemas. Os cientistas industriais estavam distantes dos processos de pesquisa e os pesquisadores, ávidos na defesa da autonomia de sua pauta de pesquisa, perduravam longe do terreno industrial e da economia. Por exemplo: a cultura material das ciências não estuda o objeto em si (vide smartphones, notebooks, televisores etc.), mas estuda diferentes técnicas e tecnologias contidas nele, principalmente por meio de quem teve a "ideia" ou o conhecimento fonte. Considerando todas essas mudanças, Castells (1999) apresenta evidências de como as organizações, por meio de interconexões, adquirem novas tecnologias como meio de entrecruzamentos sociais - indústria, universidade e sociedade -, compostos por estruturas abertas capazes de se expandir ilimitadamente e integrar os novos sujeitos.

As redes constituem a nova morfologia social de nossas sociedades, e a difusão da lógica de redes modifica de forma substancial a operação e os resultados dos processos produtivos e de experiência, poder e cultura [...] (CASTELLS,1999, p. 497).

No entanto, com a falência do regime monopolista de produção e a emergência da predominância 
financeira, esse quadro se alterou de modo radical. Ocorreu que o ciclo de capital portador de juros fez dinheiro sem trabalho.

\footnotetext{
Na equação marxista, temos D' > D. O proprietário do dinheiro investe, empresta e recebe os juros como forma de pagamento desta operação pela mera propriedade privada do dinheiro [...] Esta operação, além de econômica, é jurídica e impõe as taxas de juros e o tempo de pagamento do que é devido, desconsiderando o que irá ocorrer no processo de produção real de valor [...] Esta operação pode ser feita entre amigos, empresas, grupo de empresas, países e pelos principais agentes institucionais que atuam mundialmente, que são os fundos mutuais, os guias da gestão do sistema monetário mundial, aos quais se subordinam os fundos de pensão e os fundos dos Grupos Predominantemente Industriais (GPI), o que caracteriza um regime de predominância financeira (SILVA JÚNIOR, 2017, p. 129-130).
}

As consequências desse regime encontram-se em inúmeros campos, tendo como exemplo o jurídico, pois o ciclo financeiro comprime não apenas o ciclo do capital em função das relações sociais de produção, mas também afeta as relações sociais, em geral alterando sociabilidade e subjetividade dos cidadãos e exigindo a produção de valor real em tempo recorde do trabalho vivo. Está aí o verdadeiro problema do capital e a necessidade de fazer desaparecer o gap entre ciência e tecnologia. Nesse ponto, exemplarmente, o Future-se, no núcleo da universidade e da pesquisa, tem como papel estratégico redefinir a ciência brasileira e, por conseguinte, o conhecimento, conforme a necessidade da tecnologização societal e, sobretudo, das exigências do mercado produtivo universal. Por essa via, a racionalidade econômico-financeira interpõe-se nas práticas cotidianas da vida universitária. As pesquisas e o trabalho do pesquisador e do professor, necessariamente, apresentam-se como conhecimento-mercadoria.

\section{Considerações Finais}

O Programa Future-se é um “ovo menor" do "ovo da Serpente" da Reforma do Aparelho do Estado. Seu desenho privatista compõe o bumerangue do Plano Diretor, que nasce em 1995 e perdura até 2020, fazendo-nos voltar até ele por meio da análise de governos apensados no neoliberalismo e ainda orientados por medidas fatais do século XX, as quais organizaram e colocaram uma grande fatia de países na periferia do capitalismo mundial. O Future-se, nesse transcurso de reformas de quase três décadas, é a síntese do desprezo com a educação superior pública brasileira, que, desrespeitada por um governo provido de autoritarismo, negacionismo e entreguismo, passará de um polo de potencial progresso e prosperidade intelectual à sociedade brasileira para um polo servil de produção de valor privado.

Dada essa direção, notamos que se acentua radicalmente o viés mercantilizador das universidades estatais brasileiras em todas as versões do texto base do projeto. A racionalidade, para tal, repete-se em quaisquer aspectos das categorias do programa, das disposições preliminares aos contrato de desempenho, atingimento de resultados (traço empresarial), celebração de contratos (cunho comercial), consolidação do empreendedorismo e internacionalização.

Mostramos também como foi a Reforma do Aparelho do Estado Brasileiro, especialmente como o primeiro núcleo estratégico do Estado (formulador de políticas) operacionalizou as numerosas medidas originárias do Consenso de Washington dentro do eixo social do Brasil, o que provocou severas mudanças no cerne estrutural do país na direção do novo regime econômico, não obstante o segundo núcleo, por meio dos serviços exclusivos do Estado, como as Forças Armadas, os Três Poderes, as Polícias Federal e Civil, entre outros 
coadunados nas mesmas reformas.

Na segunda parte, demonstramos como o Estado fez e faz a mediação da economia com a sociedade civil, tendo seus serviços não exclusivos no campo competitivo que, por meio de ordenamentos jurídicos, permite a entrada do capital financeiro dentro da esfera pública. Ou seja, a lógica da Reforma do Estado se dá pela macroexpansão da esfera privada sobre a redução da esfera pública, o que resulta em perda de direitos por meio da terceirização irrestrita, do desmantelamento das CLT, entre outras reformas que abrem extenso mercado, cuja essência é mercantilizar necessidades humanas. Consequentemente, os direitos humanos, sociais e do trabalhador passam a ser ocupados pelo capital nacional e estrangeiro, na forma de oferta de serviços, razão pela qual o Estado permite a espoliação do trabalhador, ao trazer lastro para o capital financeiro.

Em 26 de maio de 2020, ocupando as últimas linhas, a mensagem n. 302 passou quase batida, decretando o "Encaminhamento ao Congresso Nacional do texto do projeto de lei que 'Institui o Programa Universidades e Institutos Empreendedores e Inovadores - Future-se”. Sem detalhes públicos do texto, que deverá passar pelo Legislativo, o governo iniciou o fim de um ciclo de reformas na universidade estatal brasileira. Sobre a racionalidade do programa, adotamos o termo estatal em vez de apenas instituições federais, porque, pela lógica apresentada e consumada no plano nacional, as universidades públicas estaduais, eventualmente, tendem a se orientar pelas mesmas medidas.

Nesse sentido, o Future-se parece ser a última ou uma das últimas pedras desse tabuleiro. Conforme mostramos, por meio de analises, fez-se necessário compreender a Reforma do Aparelho do Estado e o novo regime de acumulação financeira para dilucidar a logicidade do Programa Institutos e Universidades Empreendedoras e Inovadoras, que se caracteriza pelo poder imperativo sobre a sociabilidade dos sujeitos envolvidos com a pesquisa no âmbito acadêmico nacional, sobre sua força imperativa na mudança do trabalho do professor universitário e pesquisador, sobre o domínio do senso de produção de conhecimento para o mercado produtivo e sobre a pujança na eliminação da autonomia do trabalho científico nas universidades.

\section{Contribuição dos Autores}

Problematização e Conceitualização: Silva Júnior, J. R.; Fargoni, E. H. E.; Metodologia: Silva Júnior, J.R.; Fargoni, E. H. E.; Análise: Silva Júnior, J. R.; Fargoni, E. H. E.; Redação: Silva Júnior, J. R.; Fargoni, E. H. E.

\section{Notas}

1. BRASIL, 2019.

2. Regulamentadas pela Lei n. 9.637/1998, as Organizações Sociais (OS) são entidades de direito privado, sem fins lucrativos, cujas atividades serão dirigidas ao ensino, à pesquisa científica e ao desenvolvimento tecnológico, à cultura, à preservação do meio ambiente e à saúde, entre outras. As OS podem prestar serviços públicos, por meio da celebração de contratos de gestão com o poder público.

3. O Consenso de Washington é uma denominação dada a um encontro realizado em 1989, na cidade de Washington, entre representantes do governo norte-americano, do Fundo Monetário Internacional (FMI) e do Banco Mundial, do Banco Interamericano de Desenvolvimento, além de representantes de vários países, com o objetivo de sistematizar e produzir o consenso sobre as principais diretrizes de política econômica com base no ideário neoliberal, as quais deveriam ser implementadas pelos países participantes do encontro. Essas diretrizes abrangiam as seguintes áreas: a) disciplina fiscal; b) priorização dos gastos públicos; c) reforma tributária; d) liberalização financeira; e) regime cambial; f) liberalização comercial; g) investimento direto; h) privatização; i) desregulação; e j) propriedade intelectual. (BATISTA, 1994).

4. A Lei Bayh-Dole, ou Lei de Emendas de Patentes e Marcas Registradas (Pub. L. 96-517, 12 de dezembro de 1980), faz parte da legislação dos Estados Unidos que trata da propriedade intelectual resultante de pesquisa financiada pelo Governo Federal. Essa 
lei surgiu dos esforços do Congresso estadunidense para responder ao mal-estar econômico da década de 1970. Um dos esforços do Congresso focou em melhorar a forma de administrar as invenções criadas com mais de US\$ 75 bilhões/ano investidos em pesquisa e desenvolvimento.

5. Disponível em: https://www.camara.leg.br/proposicoesWeb/fichadetramitacao?idProposicao=2088351. Acesso em: 29 maio 2020.

6. MONTES, 2019.

7. World Class University é um padrão que delimitada um modelo de universidade ideal - produtora de conhecimento inovador e comercializável e de publicações em revistas cientificas conceituadas sob uma lógica de referência, sobretudo, no mercado global. "Para esse fim, atividades de pesquisa, publicações, citações e grandes prêmios do corpo docente [...] tornam-se as medidas mais significativas de uma universidade de classe mundial" (SHARPE, 2014, p. 3, tradução nossa)

8. Os naming rights permitem atribuir nomes de figuras notáveis do mercado, da academia aos campi, prédios da universidade e similares. Um teatro dentro do campus ou a biblioteca podem ter nomes trocados por selos e marcas do mercado, assim como suas diretrizes.

9. Disponível em: https://www.brasildefato.com.br/2019/10/16/quase-70-das-universidades-federais-rejeitam-projeto-future-se/; http://www.andifes.org.br/veja-manifestacoes-universidades-federais-sobre-future-se/; e https://educacao.uol.com.br/ noticias/2019/08/14/mais-de-40-federais-criticam-future-se-duas-rejeitam-adesao-ao-projeto.htm. Acessos em: 30 maio 2020.

10. Agência de promoção de exportações do Brasil.

\section{Referências}

ANDIFES. Lula reafirma compromisso com os reitores durante discurso na $4^{\text {a }}$ Conferência Nacional de Ciência, Tecnologia e Inovação. Portal Andifes, Brasil, 26 mai. 2010. Disponível em: http://www.andifes. org.br/lula-reafirma-compromisso-com-os-reitores-durante-discurso-na-4-conferencia-nacional-de-cienciatecnologia-e-inovacao/. Acesso em: 30 mai. 2020.

ARENDT, H. As origens do totalitarismo. São Paulo: Companhia de Bolso, 1997. (E-book. Edição para Kindle).

BATISTA, P. N. A visão neoliberal dos problemas da América-Latina. USP: São Paulo, 1994.

BAUMAN, Z. Capitalismo parasitário. Rio de Janeiro: Zahar, 2010.

BRASIL. Lei n. 10.168, de 29 de dezembro de 2000. Institui contribuição de intervenção de domínio econômico destinada a financiar o Programa de Estímulo à Interação Universidade-Empresa para o Apoio à Inovação e dá outras providências, 2000. Disponível em http://www.planalto.gov.br/ccivil_03/LEIS/L10168.htm. Acesso em: 30 mai. 2020.

BRASIL. Programa Institutos e Universidades Empreendedoras e Inovadoras - Future-se. Rio de Janeiro: Universidade Federal do Rio de Janeiro, 2019. Disponível em: https://ufrj.br/sites/default/files/imgnoticia/2019/07/projeto_de_lei_do_programa_future-se.pdf. Acesso em: 31 mai. 2020.

BRESSER-PEREIRA, L. C. Crise econômica e reforma do Estado no Brasil. São Paulo: Editora 34, 1996.

CASTELLS, M. A Sociedade em Rede. São Paulo: Paz e Terra, 1999.

CHAUÍ, M. Escritos sobre a universidade. São Paulo: Editora da UNESP, 2001.

GOMES, J. M. 21 anos de Plano Real, sistema da dívida e ajuste fiscal. Universidade e Sociedade, Brasília, v. 26, n. 57 , jan. 2016.

HARVEY, D. 17 contradições e o fim do capitalismo. São Paulo: Boitempo, 2016.

KAKUTANI, M. A morte da Verdade: Notas sobre a mentira na era Trump. Rio de Janeiro: Intrínseca, 2018. 
(Edição para Kindle).

LEHER, R. Universidade e heteronomia cultural no capitalismo dependente: um estudo a partir de Florestan Fernandes. Rio de Janeiro: Consequência, 2018.

LIMA, K. R. S. Capitalismo dependente e "Reforma Universitária Consentida": A contribuição de Florestan Fernandes para a superação dos dilemas educacionais brasileiros. REUNIÃO ANUAL DA ANPED, n. 28, Caxambu, 2005. Anais. Caxambu, 2005.

MONTES, R. Chile arde e ninguém sabe como apagar o fogo. EL PAÍS, 04 nov. 2019. Disponível em: https:// brasil.elpais.com/brasil/2019/11/02/internacional/1572723876_406423.html. Acesso em: 29 maio 2020.

PAULANI, L. Bolsonaro, o ultraliberalismo e a crise do capital. Margem Esquerda, Boitempo, São Paulo, n. 32, maio. 2019.

SALMI, J. The challenge of establishing world-class universities, Washington: The World Bank, 2009.

SCHWARTZMAN, S. et. al. Uma análise sobre o programa Future-se, proposto pelo MEC, 2019. Disponível em: https://desafiosdaeducacao.grupoa.com.br/analise-do-programafuture-se/. Acesso em: set. 2019.

SGUISSARDI, V.; SILVA JÚNIOR, J. R. Universidade pública brasileira no século XXI: Educação superior orientada para o mercado e intensificação do trabalho docente. Espacios en Blanco. Revista de Educación, Universidad Nacional del Centro de la Provincia de Buenos Aires, Buenos Aires, Argentina, n. 23, pp. 119156, jun. 2013.

SHARPE, R. What is a World Class University? A literature review. Elementa Leadership, Articles and Provocations., 2014.

SICSÚ, A. B.; SILVEIRA, M. Avanços e retrocessos no marco legal da ciência, tecnologia e inovação: Mudanças necessárias. Ciência e Cultura, São Paulo, v. 68, n. 2, p. 04-05, 2016. http://doi. org/10.21800/2317-66602016000200002

SILVA JÚNIOR, J. R. The new Brazilian University: A busca por resultados comercializáveis: para quem? 1. ed. Bauru: Canal 6, 2017.

SILVA JÚNIOR, J. R.; FARGONI, E. H. E. Mundialização da educação superior: Notas sobre economia, produção de conhecimento e impactos na sociedade civil. Revista Trabalho \& Educação, v. 28, n. 3, p. 35-49, set.-dez, 2019.

SILVA JÚNIOR, J. R; SGUISSARDI, V. Novas faces da educação superior no Brasil: Reforma do Estado e mudança na produção. Uberlândia: Navegando Publicações, 2020.

SLAUGHTER, S.; RHOADES, G. Academic capitalism and the new economy. Baltmore: Johns Hopkins University Press, 2010.

USP. Dissecando o currículo do Ministro da Educação. Jornal do Campus, 01 maio 2019. Disponível em: http://www.jornaldocampus.usp.br/index.php/2019/05/dissecando-o-curriculo-do-ministro-da-educacao/. Acesso em: 30 mai. 2020. 


\section{Sobre os Autores}

JoÃo dos Reis Silva Júnior é graduado pela Escola de Engenharia de São Carlos. Mestre em Administração e Doutor em Filosofia da Educação pela Pontifícia Universidade Católica. Pós-doutor em Sociologia Política pela Universidade Estadual de Campinas. Pós-doutor em Economia pela USP e pela University of London. Livre-docente em Educação pela USP e Professor Titular da Universidade Federal de São Carlos.

Everton Henrique Eleutério Fargoni é licenciado em Pedagogia pela Universidade Federal de São Carlos . Mestre em Educação pelo Programa de Pós-Graduação em Educação da UFSCar. Integrante do Grupo de Estudos e Pesquisa de Economia Política da Educação e Formação Humana. Membro pesquisador do eixo de pesquisa "Produção do Conhecimento" da Rede Universitas/BR.

Recebido: 02 jun. 2020

Aceito: 12 jun. 2020 